Original Research Paper

\title{
Trend Analysis of Some Indices of Extreme Rainfall Events
}

\author{
${ }^{1,2}$ Olumuyiwa Idowu Ojo, ${ }^{2}$ Femi Dakaye and ${ }^{1}$ Masengo Francois Ilunga \\ ${ }^{1}$ Department of Civil and Chemical Engineering, University of South Africa, Florida Campus, South Africa \\ ${ }^{2}$ Department of Agricultural Engineering, Ladoke Akintola University of Technology, Ogbomoso, Nigeria
}

\author{
Article history \\ Received: 18-05-2017 \\ Revised: $21-11-2017$ \\ Accepted: 30-12-2017 \\ Corresponding Author: \\ Olumuyiwa Idowu Ojo \\ Department of Civil and \\ Chemical Engineering, \\ University of South Africa, \\ Florida Campus, South Africa \\ Email: ojooi@unisa.ac.za
}

\begin{abstract}
Climate change events results in increased temperature, changing rainfall patterns, floods and droughts. These will not only affect human but also affect how environment responds to the events. In this study, analyses of the trend change of 10 indices of Extreme Rainfall Events were carried in three stations of middle belt of Nigeria namely Jos, Lokoja and Makurdi using the RclimDex software. Daily rainfall data for the 3 stations were collected for the period of 1971 to 2005 . The results from analyses of trend change of extreme rainfall indices depicted a sequence of alternating decrease and increase trends in the variables with a varying value due to population and size distribution for the study period. This inevitable climate effect needs to be adapted in order to make life and environment worthwhile.
\end{abstract}

Keywords: Trend Change, Agricultural, Environment, Extreme Rainfall, Climate

\section{Introduction}

Many studies have carried out the climate related research in different parts of the world with such studies considering the relationship between climate variability and agricultural productivity in order to establish the impact of the former on the latter (Ojo and Oni, 2001; IPCC, 2002; 2007; Chiew, 2002; Okpara, 2003; Adejuwon, 2004a). Climate change pertains generally to longer-term trends than that of climate variability (Okpara, 2003). The impacts of rainfall variability on agricultural productivity in Asia, Africa and Latin America with suitable examples in tropical Asia and Africa where agricultural productivity is sensitive to rainfall variability that eventually causes environmental and social stresses (WMO, 2000). Inter-annual rainfall variability is resulting in increased frequencies of drought and poses the greatest risk to crop yield. Study by Jones and Thornton (2002) has projected a decrease in crop yield in Africa by $10-20 \%$ by 2050 or even up to $50 \%$ due to climate change. FAO (2001) examined the effects of rainfall variability on food production; the study showed that rainfall variability is one of the main determinants of agricultural production in both developing and developed countries. Climate variability has been the principal source of fluctuations in global food production, particularly in the semi-arid tropical countries of the developing world (Sivakumar, 1997; Adejuwon, 2004b). Agricultural productivity in Nigeria is strongly linked to rainfall variability because farmers rely on rain-fed agriculture. The dry lands of Northern Nigeria have been mostly affected by the growing problem of climatic change impacts. This is because the economy of the region is predominantly agrarian rain-fed as the farmers in this area are not able to cope largely because of serious poverty level and low technological development, hence low level of copping capabilities (Ziervogel et al., 2006; Nwafor, 2007). According to Adejuwon (2004a), inter-annual rainfall variations are causes of great stress to the farming activities, crop production and crop yield in the Guinea Savanna of Nigeria in the 1990 s to early 2000. Intra-annual rainfall variability refers to the distribution of rainfall within a year (Obioha, 2008). In general, changes in rainfall variability as well as in the mean value of climate variables influence the yield of cereal crops, but because the pattern of rainfall variability is not necessarily harmful, the problems arise from extreme events and the uncertainty, which derives from the difficulty of predicting weather beyond a week (FAO, 2001). It stated that although these extreme events are inherently abrupt, random and disastrous, the risks could be reduced through improved preparedness and planning, better information, stronger institution and new technologies to minimize human and material losses (FAO, 2001). This study was therefore based on the analysis of rainfall data obtained from some meteorological stations and evaluation of temporal changes in rainfall extremes over the Sudan-sahelian belt of Nigeria from year 1971 to 2005 . 


\section{Methodology}

\section{Study Area}

North Central Nigeria is located at an elevation of 704 meters above sea level and It comprises of six states; Benue, Kogi, Kwara, Nasarawa, Niger, Plateau and including Abuja as shown in Fig. 1. This region, due to its location is characterized by tropical continental dry climate. The climate is characterized by alternate wet and dry seasons in response to the changes in pressure patterns and high temperature throughout the year at about $270^{\circ} \mathrm{C}$. Agricultural crops in the area include groundnut, cotton, millet, beans, guinea corn, cassava, yam and maize (Adejuwon, 2004b).

\section{Data Collection and Analyses}

Daily rainfall data from year 1971 to 2005 were collected from the Nigerian Meteorological Agency (NIMET). The data collected are for the meteorological stations in Jos, Lokoja and Makurdi, representing; Plateau, Kogi and Benue State, respectively in the Middle Belt of Nigeria.

\section{Data Analysis}

Rainfall data was used to generate several indices using the RClimDex software. RClimDex is a Microsoft Excel based program that provides an easy-to-use protocol for the calculation of indices of climate extremes for monitoring and detecting climate change. It was developed by Byron Gleason at the National Climate Data Centre (NCDC) of NOAA and has been used in CCI/CLIVAR workshops on climate indices from 2001. The data was processed by checking the homogeneity with the result for the analysis, while the trend in index of rainfall extreme was calculated using the Mann-Kendall test, a non-parametric test recommended by the World Meteorological Organization (WMO), to explore trends in hydro-climatological time series (Salami et al., 2002; Tosic and Unkasevic, 2005; Oguntunde et al., 2006; Dinpashoh et al., 2011). This test is applicable in cases when the data values $X$ of a time series can be assumed to obey the model:

$$
\chi=f(t)+e i
$$

where, $f(t)$ is a continuous monotonic increasing or decreasing function of time and the Residual ei can be assumed to be from the same distribution with zero mean Mann-Kendall test statistics $S$ is given by Salami et al. (2002) as:

$$
S=\sum_{k=1}^{n-1} \sum_{j=k+1}^{n} \operatorname{sgn}\left(x_{j}-x_{k}\right)
$$

where, $n$ is the length of the time series $X_{j} \ldots X_{n}$ and Sgn $(\cdot)$ is a sign function, $X_{j}$ and $X_{k}$ are values in years $j$ and $k$, respectively. The expected value of $S$ equal zero for series without trend and the variance is computed as:

$$
\sigma^{2}(S)=\frac{1}{18}\left[n(n-1)(2 n+5)-\sum_{p=1}^{q} t_{p}\left(t_{p}-1\right)\left(2 t_{p}+5\right)\right]
$$

Here $q$ is the number of tied groups and $t_{p}$ is the number of data values in $p^{\text {th }}$ group. The test statistic $Z$ is then given as:

$$
Z= \begin{cases}\frac{S-1}{\sqrt{\sigma^{2}(S)}} & \text { if } S>0 \\ 0 & \text { if } S=0 \\ \frac{S+1}{\sqrt{\sigma^{2}(S)}} & \text { if } S<0\end{cases}
$$

As a non-parametric test, no assumptions as to the underlying distribution of the data are necessary. The $Z$ statistic is then used to test the null hypothesis, $H_{o}$, which the data is randomly ordered in time, against the alternative hypothesis, $\mathrm{H}_{1}$, where there is an increasing or decreasing monotonic trend. A positive (negative) value of $Z$ indicates an upward (downward) monotone trend. $\mathrm{H}_{\mathrm{o}}$ is rejected at a particular level of significance if the absolute value of $Z$ is greater than $Z_{1-} a / 2$, where $Z_{1 \text { - }}$ $a / 2$ is obtained from the standard normal cumulative distribution tables. It should be noted that the MannKendall test is non-dimensional and does not quantify the scale or the magnitude of the trend in the units of the time series under study, but is rather a measure of the correlation of $x i$ with time and, as such, simply offers information as to the direction and a measure of the significance of the observed trends. Hobbins et al. (2001) noted that Mann-Kendall test is non-dimensional and does not quantify the scale or the magnitude of trend but the direction of trend. The Sen.'s non-parametric method will be use to estimate the slope of an existing trend. This method is good as it tends to bring out the true slope of any existing trend and researchers (Salami et al., 2002) often use it. The Sen's method can be used in cases where the trend can be assumed linear. This means that $f(t)$ in Equation (2) is equal to:

$$
f(t)=\mathrm{Q} t \pm B
$$

where, $Q$ is the slope and $B$ is a constant. To get the slope estimate $Q$ in Equation (6) we first calculate the slopes of all data value pairs as:

$Q_{i}=\frac{\chi_{j}-\chi_{k}}{j-k}$

where, $j>k$. 


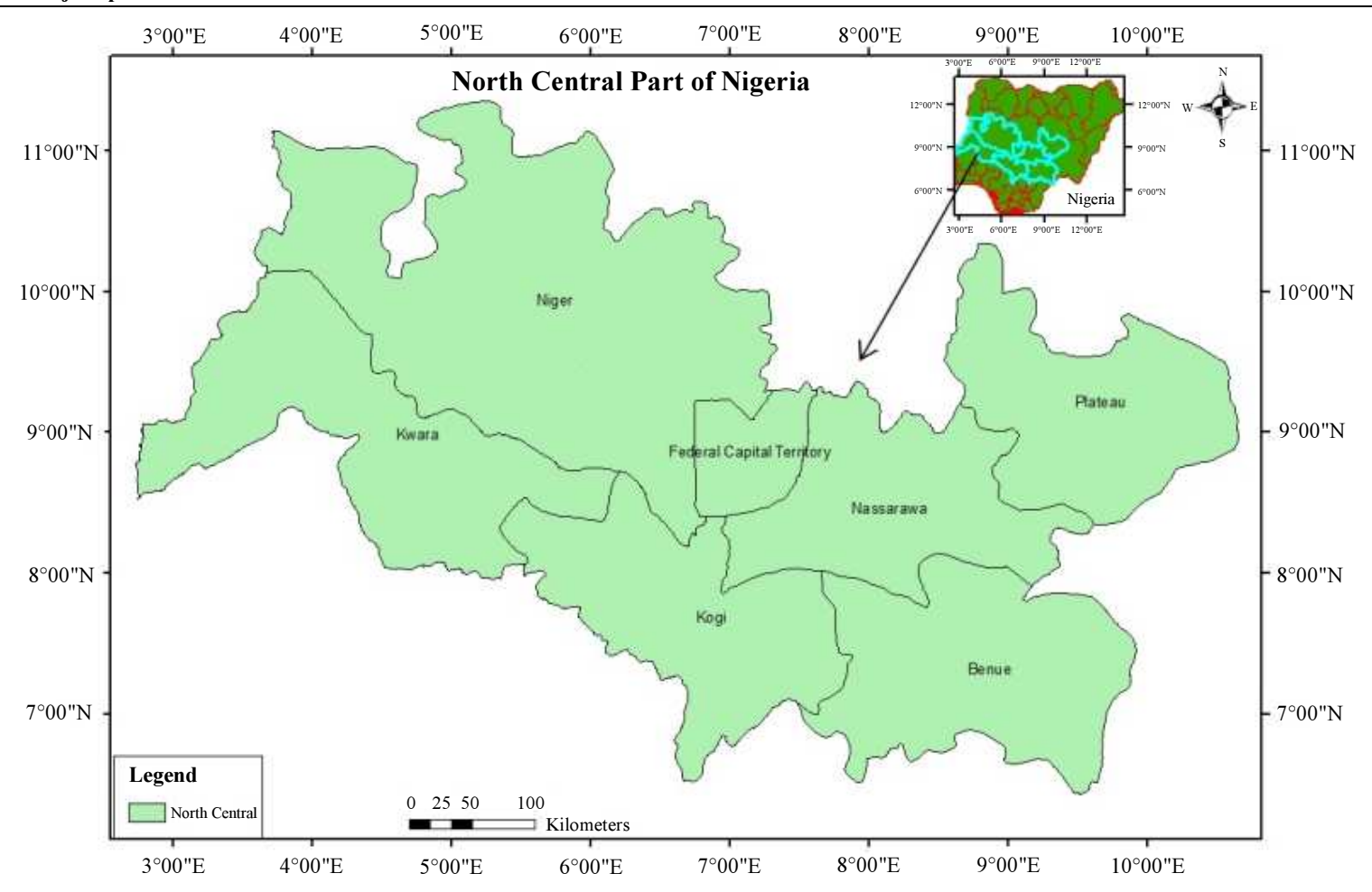

Fig. 1: Map of the study area

If there are $n$ values $x_{j}$ in the time series, we get as many as $N=n(n-1) / 2$ slope estimates $Q_{i}$. The Sen's estimator of slope is the median of these $N$ values of $Q_{i}$. Both trend and slope test are calculated with software called MAKESENS 1.0.

\section{Results and Discussion}

\section{Trend Results over Jos}

Trend statistics for 10 range of indices of extreme rainfall events over Jos for the period of 35 years; year 1971 to 2005 as presented in Table 1. The following indices: Rx 1day showed a positive trend at an increase rate of $0.175 \mathrm{~mm} / \mathrm{yr}$; CDD showed an increase rate of 0.4 day/yr; CWD had an increase rate of $0.001 \mathrm{day} / \mathrm{yr}$; while R99P showed an increase rate of $0.42 \mathrm{~mm} / \mathrm{yr}$. Furthermore, the following indices of extreme rainfall events: Rx5-day showed a negative trend at a decrease rate of $-0.291 \mathrm{~mm} / \mathrm{yr}$; SDII showed a decrease rate of $0.027 \mathrm{~mm} / \mathrm{day} / \mathrm{yr}$; $\mathrm{R} 10$ showed a decrease rate of -0.125 day/yr; while R95P showed a decrease rate of - 0.182 $\mathrm{mm} / \mathrm{yr}$. Exceptionally, R20 and PRCPTOT showed significant negative trend at a decrease rate of -0.129 day $/ \mathrm{yr}(\mathrm{p}<0.1)$; and $-4.39 \mathrm{~mm} / \mathrm{yr}(\mathrm{p}<0.05)$ respectively.

\section{Trend Results over Lokoja}

Trend statistics for a range of indices of extreme rainfall events over Lokoja for the period of 35 years; year 1971 to 2005 was presented in Table 2. The following indices: Rx 1day showed a positive trend at an increase rate of $0.133 \mathrm{~mm} / \mathrm{yr}$; SDII showed an increase rate of $0.044 \mathrm{~mm} / \mathrm{day} / \mathrm{yr} ; \mathrm{R} 20$ had an increase rate of 0.091 day/yr; R95P showed an increase rate of $0.137 \mathrm{~mm} / \mathrm{yr}$; R99P showed an increase rate of $0.182 \mathrm{~mm} / \mathrm{yr}$; while PRCPTOT showed an increase rate of $2.137 \mathrm{~mm} / \mathrm{yr}$. Furthermore, the following indices of extreme rainfall events: Rx5-day showed a negative trend at a decrease rate of $-1.30 \mathrm{~mm} / \mathrm{yr}$; R10 showed a decrease rate of - 0.12 day/yr; CDD showed a decrease rate of -0.125 day/yr; while CWD showed a decrease rate of - 0.038 day/yr.

\section{Trend Results over Makurdi}

Trend statistics for a range of indices of extreme rainfall events over Makurdi for the period of 35 years; year 1971 to 2005 was presented in Table 3. The following indices: Rx5-day showed a positive trend at an increase rate of $0.001 \mathrm{~mm} / \mathrm{yr}$; SDII showed an increase rate of $0.02 \mathrm{~mm} / \mathrm{day} / \mathrm{yr}$; while $\mathrm{R} 20$ had an increase rate of $0.001 \mathrm{day} / \mathrm{yr}$. Furthermore, the following indices of extreme rainfall events: Rx1-day showed a negative trend at a decrease rate of $-0.211 \mathrm{~mm} / \mathrm{yr}$; R10 showed a decrease rate of $-0.063 \mathrm{day} / \mathrm{yr}$ and $\mathrm{CDD}$ showed a decrease rate of -0.183 day/yr. Others such as R95P showed a decrease rate of $-0.596 \mathrm{~mm} / \mathrm{yr}$., R99P showed a decrease rate of -0.211 , while PRCPTOT showed a decrease rate of $-0.779 \mathrm{~mm} / \mathrm{yr}$. Exceptionally, CWD showed a significant negative trend at a decrease rate of 0.105 day $/ \mathrm{yr}(\mathrm{p}<0.05)$. 
Table 1: Trend analysis of some indices of extreme rainfall events over Jos

\begin{tabular}{|c|c|c|c|c|c|}
\hline Time series & First year & Last year & Test Z & Significant. & Q \\
\hline $\mathrm{R} \times 1$ day & 1971 & 2005 & 0.80 & & 0.18 \\
\hline $\mathrm{R} \times 5$-day & 1971 & 2005 & -0.44 & & 0.29 \\
\hline SD11 & 1971 & 2005 & -1.16 & & 0.03 \\
\hline R10 & 1971 & 2005 & -1.61 & & 0.13 \\
\hline R20 & 1971 & 2005 & -1.75 & + & 0.13 \\
\hline CDD & 1971 & 2005 & 1.61 & & 0.40 \\
\hline CWD & 1971 & 2005 & -0.67 & & 0.01 \\
\hline R95P & 1971 & 2005 & -0.30 & & 0.18 \\
\hline \multicolumn{6}{|l|}{ R99P } \\
\hline \multirow[t]{2}{*}{ PRCPTOT } & 1971 & 2005 & 0.95 & & 0.42 \\
\hline & 1971 & 2005 & 1.97 & * & -4.39 \\
\hline
\end{tabular}

Table 2: Trend analysis of some indices of extreme rainfall events over Lokoja

\begin{tabular}{lllrr}
\hline Time series & First year & Last year & Test Z & Significant. \\
\hline R $\times 1$ day & 1971 & 2005 & 0.47 & 0.130 \\
R×5-day & 1971 & 2005 & -1.55 & -1.300 \\
SD11 & 1971 & 2005 & 1.02 & 0.040 \\
R10 & 1971 & 2005 & -0.85 & 0.120 \\
R20 & 1971 & 2005 & 1.47 & 0.090 \\
CDD & 1971 & 2005 & -0.36 & 0.130 \\
CWD & 1971 & 2005 & -1.22 & 0.040 \\
R95P & 1971 & 2005 & 0.14 & 0.140 \\
R99P & 1971 & 2005 & 0.75 & 0.180 \\
PRCPTOT & 1971 & 2005 & 0.57 & 2.147 \\
\hline
\end{tabular}

Table 3: Trend analysis of some indices of extreme rainfall events over Makurdi

\begin{tabular}{lllrl}
\hline Time series & First year & Last year & Test Z & Significant. \\
\hline R $\times 1$ day & 1971 & 2000 & -0.68 & 0.210 \\
R×5-day & 1971 & 2000 & -0.04 & 0.000 \\
SD11 & 1971 & 2000 & 0.39 & 0.020 \\
R10 & 1971 & 2000 & -0.40 & 0.060 \\
R20 & 1971 & 2000 & -0.25 & 0.000 \\
CDD & 1971 & 2000 & -0.56 & 0.180 \\
CWD & 1971 & 2000 & -2.12 & 0.110 \\
R95P & 1971 & 2000 & -0.34 & 0.590 \\
R99P & 1971 & 2000 & -0.68 & 0.210 \\
PRCPTOT & 1971 & 2000 & -0.11 & 0.789 \\
\hline
\end{tabular}

\section{Discussion}

In order to understand the nature of climatic variability within the climate system, it is necessary to study its components in a systematic way, therefore analyzed was carried out in terms of changes in the statistical distribution of the local rainfall. The study identified decreasing trends in some indices of extreme rainfall event across the study area. At Jos, the study specifically found significant negative trends in R20 and PRCPTOT, while other indices: Rx5-day, SDII, R10 and R95P also showed decreasing trend. Furthermore, at Lokoja, the study identified decline trend in Rx5-day, R10, CDD and CWD although none of these indices was statistically significant. At Makurdi, significant negative trend was specifically found in CWD. While other indices: Rx1day, R10, CDD, R95P, R99P and PRCPTOT also showed negative trend but not at a significant decrease rate. These findings are in line with the study of Abdulkadir et al. (2009) which reported that decline trend was identified in moisture effectiveness that intensified moisture stress across the belt in the last six decades signifying the fact that decrease moisture effectiveness is a prime aridity factor in the subregion. By these results, the Sudan-sahelian belt is increasingly vulnerable to crops failure due to increased Aridity (AI), late onset and early retreat of rainfall resulting to shorter hydrologic growing season already obvious across the belt. The trend confirm the effect of climate change and is disastrous to agriculture, as delayed onset often leads to late planting of crops, while premature cessation leads to wilting and dryness of the crops before maturity, there by endangering food security in the belt.

\section{Conclusion}

The information provided how the mean values changed over time and change in the statistical distribution of the data. The results showed that all indices have decreased at Jos. Likewise decreased trends at Lokoja. In the same vein, indices have also declined at Makurdi. 
The results from the analysis, presented scientific information on magnitude, departures from long-term conditions and trends in rainfall in all the three stations but with a varying value due to population and size distribution, these inevitable climate effects, which needs to be adapted to may cost excessive spending in order to make life and environment worthwhile. To be able monitor indices of any extreme events accurately across each state in Nigeria, the Government needs to invest in setting up weather station in every local government to cover for the lags in accuracy of data acquired when showing the spatial distribution of weather parameters. In addition, results of rainfall studies in any region can help the decision maker to manage their water resources, agricultural, environment and other water related projects.

\section{Acknowledgement}

The authors would like to thank NMET for providing the data and UNISA for paying the processing fees.

\section{Author's Contributions}

Olumuyiwa Idowu Ojo and Femi Dakaye: Worked in the preparation, development and analysis.

Masengo Francois Ilunga: Vetted the manuscript for publication.

\section{Ethics}

Authors declared that there is no ethical issue that may arise after the publication of this manuscript.

\section{References}

Abdulkadir, A. and M.T. Usman, 2009. An Assessment of Eco-Climatic Characteristics in the SudanoSahelian Belt of Nigeria. Kampala, Uganda, International Book of Abstract, pp: 111.

Adejuwon, J.O., 2004a. Food crop production in Nigeria: Present effects of climate variability. Clim. Res., 30: 53-60.

Adejuwon, S.A., 2004b. Impacts of climate variability and climate change on crop yield in Nigeria. Proceedings of the Conference Centre, Workshop on Assessment and Adaptation of Impacts of Climate Change (ICC' 04), Obafemi Awolowo University, Ile-Ife, pp: 271-279.

Chiew, M., 2002. Climate Variability Program. CRC for Catchment's Hydrology, Dewey and Wayn; Pearl Millet for Grain, USDA-ARS.

Dinpashoh, Y., D. Jhajharia, A. Fakheri-Fard, V.P. Singh and E. Kahya, 2011. Trends in reference crop evapotranspiration over Iran. J. Hydrol. 339: 422-433.

FAO, 2001. Climate variability and change: A challenge for sustainable agricultural production. Committee Agric. Publishers.
IPCC, 2002. Climate Change 2001: Synthesis Report. In: A Contribution of Working Group I, II and III to the Third Assessment Report of the Intergovernmental Panel on Climate Change, Watson, R.T., (Ed.), Cambridge University Press, Cambridge, UK, pp: 239-397.

IPCC, 2007. Climate Change: Synthesis Report. 1st Edn. Cambridge University Press, Cambridge.

Jones, P.G. and P.K. Thornton, 2002. Croppers to livestock keepers: Livelihood transition to 2010 in Africa due to climate change. Global Environmental Change, World Health Organization, Geneva, Switzerland.

Nwafor, J.C., 2007. Global climate change: The driver of multiple causes of flood intensity in sub-Saharan Africa. Proceedings of the International Conference on Climate Change and Economic Sustainability Held at Nnamdi Azikiwe University, Jul. 25-25, Enugu, Nigeria, pp: 67-72.

Obioha, M., 2008. Climate change, population drift and violent conflict over land resources in North Eastern Nigeria. J. Human Ecol., 23; 311-324. DOI: $1080 / 09709274.2008 .11906084$

Oguntunde, P.G., J. Friensen, N. van de Giesen and H.H.G. Saveniji, 2006. Hydroclimatology of the Volta river basin in West Africa: Trends and variability from 1901 to 2002. Phys. Chem. Earth, 31: 1180-1188. DOI: 10.1016/j.pce.2006.02.062

Ojo, K. and F. Oni, 2001. Fundamentals of Physical and Dynamic Climatology. 1st Edn. SEDEC Publishers, Lagos, ISBN-10: 9783577298, pp: 477.

Okpara, E.E., 2003. Complementarily between densification and climate change conventions responses to unpredictable rainfall patterns in Nigeria. Dry Belt. Prod. Committee Agric. Publishers.

Salami, T., A. Maatta, P. Anttila, T. Ruoho-Airola and T. Amnell et al., 2002. Detecting trends of annual values of atmospheric pollutants by the Mann-Kendall test and Sen's Slope estimate. Publications Air Quality.

Sivakumar, M.V.K., 1997. Climate variability and food production. Proceedings of the forth ninth session of the Executive council of the World Meteorological Organization, (WMO' 97), Geneva, Switzerland, pp: 10-20.

Tosic, I. and M. Unkasevic, 2005. Analysis of precipitation series for Belgrade. Thor. Applied Climatol., 80: 67-77. DOI: $10.1007 / \mathrm{s} 00704-004-0076-1$

WMO, 2000. Climate, weather and agriculture, a paper presented at world food summit, Rome. World Meteorological Organization.

Ziervogel, G., A. Nyong, B. Osman, C. Conde and S. Cortes et al., 2006. Climate variability and change: Implications for households' food security. Proceedings of the Assessment of Impacts and Adaptations to Climate Change (ACC' 06), Washington DC, USA, pp: 678-691. 